\title{
Opioids for chronic pain: a knowledge assessment of nonpain specialty providers
}

This article was published in the following Dove Press journal: Journal of Pain Research

10 March 2016

Number of times this article has been viewed

\section{Amy CS Pearson \\ Jason S Eldrige \\ Susan M Moeschler \\ W Michael Hooten \\ Department of Anesthesiology, \\ Mayo Clinic, Rochester, MN, USA}

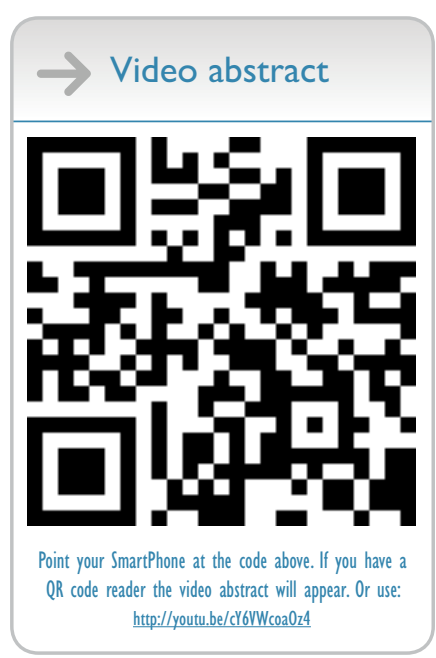

Correspondence: W Michael Hooten Department of Anesthesiology, Mayo Clinic, 200 First St SW, Charlton I- I45, Rochester, MN 55905, USA

Tel + I 5072669977

Email hooten.william@mayo.edu
Introduction: Although the majority of opioids in the US are prescribed by nonpain specialists, these providers often report inadequate training in chronic pain management and opioid prescribing. The extent of health care providers' knowledge of opioid prescribing for chronic pain has not been well established. The purpose of this study was to assess knowledge about the use of opioids for chronic pain among health care providers seeking pain-focused continuing medical education.

Materials and methods: The study participants $(n=131)$ were recruited at a pain-focused continuing medical education conference for nonpain specialists. Upon commencement of the conference, the KnowPain-50 survey was completed. The survey comprised 50 questions, and 18 questions were related to opioid management. The focus of each opioid question was further categorized as either medicolegal $(n=7)$ or clinical $(n=11)$.

Results: The majority of study participants were male physicians with a mean age of 51.8 years. The proportion of correct responses to the 50 -item survey was $72 \%$. The proportion of correct responses to the 32 nonopioid questions was $74 \%$, and the proportion of correct responses to the 18 opioid questions was $69 \%(P<0.001)$. Similarly, the proportion of correct responses to the seven medicolegal opioid questions was $74 \%$, and the proportion of correct responses to the eleven clinical opioid questions was $67 \%(P<0.001)$.

Conclusion: Health care providers demonstrated gaps in knowledge about the use of opioids for chronic pain. Lower scores on clinically based opioid questions may indicate an opportunity to provide focused educational content about this area of practice. This information could be helpful in designing future educational modules for nonpain providers.

Keywords: chronic pain, opioids, prescription, continuing medical education

\section{Introduction}

The number of opioid prescriptions in the USA has risen dramatically over the past 25 years, increasing from 76 million in 1991 to 259 million in $2012 .{ }^{1}$ With the rise in opioid prescriptions, the abuse and diversion of prescription opioids has increased, ${ }^{2}$ and prescribers face the challenge of balancing the risks and potential benefits of these medications. ${ }^{3}$ As more than $40 \%$ of opioid prescriptions are written by general or family practitioners, ${ }^{4}$ the opioid prescribing patterns of this group of health care professionals have an important influence on the general public health of US residents.

A majority of primary care providers prescribe opioids for pain. ${ }^{5-9}$ However, many primary care providers find opioid prescribing a significant challenge. For example, many report that their formal training about opioid prescribing was inadequate..$^{5,6,10-12}$ Furthermore, they report concerns about medication side effects, 
regulatory scrutiny, addiction, and opioid misuse. . $^{7,10,12-16}$ A recent systematic review found that most physicians do not follow all recommendations regarding safe opioid prescribing, and significant knowledge gaps were identified. ${ }^{17}$ Primary care providers who have received pain management education after formal training reported the greatest level of confidence with prescribing opioids for chronic pain. ${ }^{18}$

Few surveys exist that assess the knowledge of nonpain specialty providers about the management of chronic pain. The KnowPain-50 survey was developed specifically to assess pain management education among physicians. ${ }^{19}$ While the survey covers a broad range of chronic pain topics frequently encountered in the primary care setting, at least one-third of the test specifically addresses opioid prescribing. Thus, the purpose of this study was to assess the knowledge about prescribing opioids for chronic pain among nonpain specialty providers seeking pain-focused continuing medical education (CME).

\section{Methods}

\section{Study participants}

The participants in this study were health care providers with prescription privileges seeking CME about pain management. All providers were nonpain specialists attending a course entitled "Pain Medicine for the Non-Pain Specialist". Eligible participants included physicians, physician assistants, and nurse practitioners. A total of 219 health care providers attended the CME course and 131 (60\%) completed the KnowPain-50 survey. Three surveys were excluded due to missing data, and the final cohort comprised 128 surveys. Following submission to Mayo Foundation Institutional Review Board (IRB) for ethics approval, it was determined that the research activity did not require IRB review in accordance with the Code of Federal Regulations (45 CFR 46). ${ }^{20}$ The Mayo Foundation Institutional Review Board did not require written informed consent be obtained from the study participants because all data was de-identified and participation was voluntary.

\section{Study setting}

The CME conference was held in March 2013 at a conference center over the course of 3 days; 30-minute lectures were delivered from 8 am to 12:30 pm. Each lecturer presented information using slides projected on a centrally located screen, and participants were allowed to ask questions after each lecture. The conference was sponsored by a tertiary referral medical center's CME department.

Upon commencement of the conference, the attendees were asked to complete the KnowPain-50 survey. The
KnowPain-50 survey was administer in paper format, and all attendees were given adequate time to complete the survey.

\section{Data collection}

\section{Demographics and practice characteristics}

Participants were asked to report basic demographic data, including age, sex, years of practice, and professional training (eg, physician, physician assistant/nurse practitioner).

\section{KnowPain-50}

The KnowPain-50 survey comprised 50 questions. ${ }^{19}$ Eighteen of the 50 questions were related to opioid management and the remaining 32 questions were related to general knowledge about pain medicine. The focus of each opioid question was further categorized as either medicolegal $(n=7)$ or clinical $(n=11)$. All medicolegal questions contained the words or phrases "investigated", "illegal", "not lawful", "state and federal requirements", or "federal regulations". The clinical questions pertained to the clinical management of pain with opioids.

The survey was scored according to the approach described by Harris et al. ${ }^{19}$ Five questions used a multiplechoice single response format; correct single responses were awarded 5 points and incorrect single responses were awarded 0 points. One of the five multiple-choice questions was a clinical question about opioids ("By far the most common adverse side effect of opioid therapy is:"). The remaining 45 questions were answered using a Likert scale ranging from 1 to 6 , where $1=$ strongly agree; $2=$ agree; $3=$ somewhat agree; $4=$ somewhat disagree; $5=$ disagree; $6=$ strongly disagree. The correct response for 25 of the Likert questions was the negative (strongly disagree, disagree, somewhat disagree), and the correct response for the remaining 20 Likert questions was the affirmative (strongly agree, agree, somewhat agree). All responses to the Likert questions were converted to a 0 - to 5-point scale, where the "strongly agree" or "strongly disagree" correct responses were awarded 5 points, and all other responses were awarded a sequentially diminishing number of points. For example, for questions where the correct response was the negative, 5 points were awarded for the response " $6=$ strongly disagree", 4 points were awarded for the response " $5=$ disagree", 3 points were awarded for the response " $3=$ somewhat disagree", and so on until 0 points were awarded for the response " $6=$ strongly agree". Alternatively, for questions where the correct response was the affirmative, 5 points were awarded for the response " $1=$ strongly agree", 4 points were awarded for the response " $5=$ agree", 3 points were awarded for the response " $3=$ somewhat agree", and so on until 0 points were awarded for the response 
" $6=$ strongly disagree". The maximum possible points for the 50 -item survey were 250 .

\section{Statistical analysis}

The mean and standard deviation $( \pm$ ) (age, years in practice), or proportion (sex) were reported for the demographic and practice characteristics. For the Likert questions, test responses awarded 3-5 points were categorized as correct responses and test responses awarded 0-2 points were categorized as incorrect. The proportion of correct responses was determined for the entire 50-item survey. The proportion of correct responses for the 32 nonopioid questions and 18 opioid questions were compared using the chi-square $\left(\chi^{2}\right)$ test. The proportion of correct responses for the eleven clinical opioid questions and seven medicolegal opioid questions were compared in a similar manner. The correlations between the demographic (age, sex) and practice characteristics (years in practice) and the proportion of correct responses to the entire 50-item survey, 32 nonopioid questions, and 18 opioid questions were assessed using Spearman's correlation coefficient $(\rho)$. Two-sided tests were used in all analyses, and the level of significance for all statistical tests was set at 0.05 . Statistical analyses were carried out using the IBM SPSS Statistics (version 21.0, IBM Corporation, Armonk, NY, USA).

\section{Results}

\section{Demographic and practice characteristics}

The demographic and practice characteristics are shown in Table 1 . Physicians were predominantly male (68\%), whereas nonphysicians were predominantly female (80\%). Physicians were also older $(51.8 \pm 11.4$ years $)$ compared with nonphysicians $(39.6 \pm 10.3$ years $)(P<0.001)$.

\section{KnowPain-50 responses}

Table 2 shows the frequency of responses to the 32 nonopioid questions. Table 3 shows the frequency of responses to the seven medicolegal and eleven clinical opioid questions.

The proportion of correct responses to the entire 50-item survey was $72 \%$. The proportion of correct responses to the 32 nonopioid questions was $74 \%$, and the proportion of correct responses to the 18 opioid questions was $69 \%$ $\left(\chi^{2}=13.5, P<0.001\right)$. Similarly, the proportion of correct responses to the seven medicolegal opioid questions was $74 \%$, and the proportion of correct responses to the eleven clinical opioid questions was $67 \%\left(\chi^{2}=12.1, P<0.001\right)$.

No significant correlations were found between the demographic (age, sex) or practice characteristics (years in practice) and the proportion of correct responses to the entire 50 -item survey, the 33 nonopioid questions, or the 17 opioid questions (all Spearman's $\rho<13.0$; all $P>0.1$ ).

\section{Discussion}

One of the main findings of this study was that nonpain specialists seeking CME content about pain medicine scored significantly lower on questions about opioids compared with nonopioid-related questions. When the focus of the opioid questions was further categorized as either medicolegal or clinical, the respondents scored significantly lower on the clinical compared with the medicolegal opioid questions.

The majority of respondents were confident in their ability to pass an investigation of their opioid prescribing practices and in their ability to find and understand state and federal requirements related to prescribing opioids. This is similar to findings by Wolfert et al, ${ }^{16}$ who reported that $59 \%$ of Wisconsin physicians were not concerned about their opioid prescribing practices being investigated. However, over $40 \%$ of these physicians responded, "do not know" to specific questions about state and federal requirements, demonstrating poor applied knowledge about these requirements. In a separate survey of family medicine physicians, the levels of concern about addiction, diversion, dependence, regulatory scrutiny, and side effects due to opioid use were investigated. ${ }^{8}$ In this group of physicians, the responses varied widely, although they tended to have less concerns for regulatory scrutiny and diversion compared with physical dependence and tolerance. ${ }^{8}$

On the KnowPain-50 survey, participants scored significantly lower on questions about opioids compared with nonopioid-related questions. More specifically, the proportion of correct scores ranged from $45 \%$ to $55 \%$ on several key clinically related opioid questions, including

Table I Demographic and practice characteristics

\begin{tabular}{|c|c|c|c|c|}
\hline Characteristics & Total $(n=128)$ & Physician $(n=108)$ & NP/PA $(n=20)$ & $P$-value \\
\hline Sex, male/female, $\mathrm{n}$ & $74 / 54$ & $73 / 35$ & $1 / 19$ & $<0.001$ \\
\hline Age, years, mean $\pm S D$ & $49.5 \pm 12.0$ & $51.8 \pm 11.4$ & $39.6 \pm 10.3$ & $<0.001$ \\
\hline Years in practice, mean \pm SD & $18.2 \pm 0.37$ & $20.4 \pm 1 \mathrm{I} .4$ & $8 \pm 6.5$ & $<0.001$ \\
\hline
\end{tabular}

Abbreviations: NP/PA, nurse practitioner/physician assistant; SD, standard deviation. 
Table 2 Proportion of correct responses to 32 nonopioid questions of the KnowPain-50 survey

\begin{tabular}{|c|c|c|c|c|c|c|c|}
\hline Nonopioid questions & $\begin{array}{l}\text { Strongly } \\
\text { agree }\end{array}$ & Agree & $\begin{array}{l}\text { Somewhat } \\
\text { agree }\end{array}$ & $\begin{array}{l}\text { Somewhat } \\
\text { disagree }\end{array}$ & Disagree & $\begin{array}{l}\text { Strongly } \\
\text { disagree }\end{array}$ & $\begin{array}{l}\text { Percent } \\
\text { correct }\end{array}$ \\
\hline $\begin{array}{l}\text { Pain assessment includes pain level/emotionality/ } \\
\text { functionality }\end{array}$ & $53(41 \%)^{*}$ & $70(55 \%)^{*}$ & $4(3 \%) *$ & $0(0 \%)$ & $\mathrm{I}(\mathrm{l} \%)$ & $0(0 \%)$ & $99 \%$ \\
\hline $\begin{array}{l}\text { Early return to activities is a primary goal after } \\
\text { onset of back pain }\end{array}$ & $54(42)^{*}$ & $57(44)^{*}$ & $13(10)^{*}$ & $3(2)$ & $\mathrm{I}(\mathrm{I})$ & $0(0)$ & 95 \\
\hline $\begin{array}{l}\text { Antidepressants do not improve function in } \\
\text { chronic pain patients }\end{array}$ & $2(2)$ & $4(3)$ & $3(2)$ & $22(17)^{*}$ & $74(58)^{*}$ & $23(18)^{*}$ & 93 \\
\hline $\begin{array}{l}\text { Physical exercise worsens pain/function in } \\
\text { patients with arthritis }\end{array}$ & $2(2)$ & $3(2)$ & $4(3)$ & $8(6)^{*}$ & $53(4 I)^{*}$ & $58(45)^{*}$ & 92 \\
\hline Pain complaints and disability always correlate & $2(2)$ & $3(2)$ & $6(5)$ & $15(12)^{*}$ & $70(55)^{*}$ & $32(25)^{*}$ & 92 \\
\hline Interdisciplinary treatment reduces disability/pain & $4 \mathrm{I}(32)^{*}$ & $59(46) *$ & $17(13)^{*}$ & $5(4)$ & $4(3)$ & $2(I)$ & 91 \\
\hline CBT is effective/apply early in the chronic pain treatment & $19(14)^{*}$ & $46(36)^{*}$ & $50(40)^{*}$ & II (8) & $2(2)$ & $0(0)$ & 90 \\
\hline I understand surgical indications for acute herniated disc & $15(12)^{*}$ & $49(38)^{*}$ & $42(33)^{*}$ & $15(12)$ & $5(4)$ & $2(2)$ & 88 \\
\hline $\begin{array}{l}\text { Gluteal myofascial pain and sciatica can have similar } \\
\text { distribution }\end{array}$ & $12(9)^{*}$ & $69(54)^{*}$ & $29(23)^{*}$ & $8(6)$ & $10(8)$ & $0(0)$ & 86 \\
\hline $\begin{array}{l}\text { Majority of cases, technology determines cause of } \\
\text { chronic pain }\end{array}$ & $2(2)$ & $3(2)$ & $16(13)$ & $26(21)^{*}$ & $60(47)^{*}$ & $21(17)^{*}$ & 85 \\
\hline $\begin{array}{l}\text { Psychosocial factors predict back surgery outcomes } \\
\text { better than physical characteristics }\end{array}$ & $12(9)^{*}$ & $4 \mathrm{I}(32)^{*}$ & $55(43)^{*}$ & II (8) & $9(7)$ & $0(0)$ & 84 \\
\hline $\begin{array}{l}\text { I understand how to diagnose and treat different } \\
\text { types of pain }\end{array}$ & $6(5)^{*}$ & $44(34)^{*}$ & $56(44)^{*}$ & $12(9)$ & $5(4)$ & $4(3)$ & 83 \\
\hline A placebo can be used to determine if pain is real & $2(2)$ & $4(3)$ & $16(13)$ & $13(10)^{*}$ & $62(48)^{*}$ & $31(24)^{*}$ & 82 \\
\hline Nerve injuries can produce chronic neuropathic pain & $6(5) *$ & $44(34)^{*}$ & $55(43)^{*}$ & $14(\mathrm{II})$ & $9(7)$ & $0(0)$ & 82 \\
\hline $\begin{array}{l}\text { I am comfortable taking pain history/ordering pain } \\
\text { medications }\end{array}$ & $15(12)^{*}$ & $44(34)^{*}$ & $44(34)^{*}$ & $19(14)$ & $4(3)$ & $2(2)$ & 80 \\
\hline Pain out of proportion to the cause indicates drug abuse & $0(0)$ & $I(I)$ & $28(22)$ & $29(23)^{*}$ & $64(50)^{*}$ & $6(5)^{*}$ & 78 \\
\hline MRI findings are consistently predictive of pain & $4(3)$ & $12(9)$ & $14(\mathrm{II})$ & $15(12)^{*}$ & $52(4 I)^{*}$ & $31(24)^{*}$ & 76 \\
\hline $\begin{array}{l}\text { I can assess function/activity status with careful } \\
\text { questioning }\end{array}$ & $8(6)^{*}$ & $43(34)^{*}$ & $46(36)^{*}$ & $14(\mathrm{II})$ & $13(10)$ & $4(3)$ & 76 \\
\hline Best therapy for fibromyalgia. Answer: aerobic exercise & $96(75)^{* *}$ & - & - & - & - & $32(25)$ & 75 \\
\hline $\begin{array}{l}\text { Distractibility from pain indicates absence of high } \\
\text { pain intensity }\end{array}$ & $0(0)$ & $8(6)$ & $32(24)$ & $37(29)^{*}$ & $46(36)^{*}$ & $5(4)^{*}$ & 69 \\
\hline Patients may sleep in spite of severe pain & $2(2) *$ & $47(36)^{*}$ & $4 I(3 I)^{*}$ & $15(12)$ & $21(16)$ & $2(2)$ & 69 \\
\hline $\begin{array}{l}\text { Spinal cord/CNS generate neuropathic pain/sensitivity } \\
\text { to touch }\end{array}$ & $11(8) *$ & $54(42)^{*}$ & $24(19)^{*}$ & $13(10)$ & $23(18)$ & $3(2)$ & 69 \\
\hline Daily chronic pain is unlikely to have a clear cause or cure & $11(8) *$ & $36(28)^{*}$ & $39(3 \mathrm{I})^{*}$ & $26(20)$ & $12(9)$ & $4(3)$ & 67 \\
\hline $\begin{array}{l}\text { High pain scores with minimal pathology indicates } \\
\text { exaggeration }\end{array}$ & $3(2)$ & II (9) & $38(30)$ & $24(19)^{*}$ & $45(35)^{*}$ & $7(5)^{*}$ & 60 \\
\hline $\begin{array}{l}\text { Diagnosis of diffuse pain with insomnia/fatigue/headache/ } \\
\text { dizziness. Answer: fibromyalgia }\end{array}$ & $76(59)^{* *}$ & - & - & - & - & $52(4 I)$ & 59 \\
\hline $\begin{array}{l}\text { Pain management with analgesics is effective in most } \\
\text { patients }\end{array}$ & $2(2)$ & $22(17)$ & $33(26)$ & $30(24)^{*}$ & $33(26)^{*}$ & $8(6)^{*}$ & 56 \\
\hline $\begin{array}{l}\text { Changes in vital signs are reliable indicators of pain } \\
\text { severity }\end{array}$ & $3(3)$ & $13(10)$ & $42(33)$ & $33(26)^{*}$ & $32(25)^{*}$ & $5(4) *$ & 55 \\
\hline $\begin{array}{l}\text { Drugs with similar response to anticonvulsant/analgesic } \\
\text { antidepressants for neuropathic pain. Answer: opioids }\end{array}$ & $61(48)^{* *}$ & - & - & - & - & $67(52)$ & 48 \\
\hline $\begin{array}{l}\text { Back pain radiates down leg(s), EMG/NCS are usually } \\
\text { useful for making a diagnosis }\end{array}$ & $I(I)$ & $22(17)$ & $49(38)$ & $23(18)^{*}$ & $30(24)^{*}$ & $3(2)^{*}$ & 44 \\
\hline $\begin{array}{l}\text { True statement regarding COX- } 2 \text { inhibitors. Answer: } \\
\text { no more effect than nonselective NSAIDs }\end{array}$ & $54(42)^{* *}$ & - & - & - & - & $74(58)$ & 42 \\
\hline SSRIs are effective treatment for neuropathic pain & $7(5)$ & $39(3 I)$ & $36(28)$ & $21(16)^{*}$ & $20(15)^{*}$ & $5(4)^{*}$ & 35 \\
\hline $\begin{array}{l}\text { Anticonvulsants have established efficacy for } \\
\text { musculoskeletal, nociceptive, or idiopathic pain }\end{array}$ & $4(3)$ & $57(45)$ & $39(30)$ & $20(15)^{*}$ & $7(5)^{*}$ & $\mathrm{I}(\mathrm{I})^{*}$ & 21 \\
\hline
\end{tabular}

Notes: *Correct answer. **Multiple-choice single answer question where data for correct answer is shown in the "Strongly agree" column, and data for incorrect answer is shown in the "Strongly disagree" column.

Abbreviations: CBT, cognitive behavioral therapy; CNS, central nervous system; COX-2, cyclooxygenase-2; EMG/NCS, electromyography/nerve conduction studies; MRI, magnetic resonance imaging; NSAIDs, nonsteroidal anti-inflammatory drugs; SSRIs, selective serotonin re-uptake inhibitors. 
Table 3 Proportion of correct responses to seven medicolegal and eleven clinical opioid questions of the KnowPain-50 survey

\begin{tabular}{|c|c|c|c|c|c|c|c|}
\hline Opioid questions & $\begin{array}{l}\text { Strongly } \\
\text { agree }\end{array}$ & Agree & $\begin{array}{l}\text { Somewhat } \\
\text { agree }\end{array}$ & $\begin{array}{l}\text { Somewhat } \\
\text { disagree }\end{array}$ & Disagree & $\begin{array}{l}\text { Strongly } \\
\text { disagree }\end{array}$ & $\begin{array}{l}\text { Percent } \\
\text { correct }\end{array}$ \\
\hline \multicolumn{8}{|l|}{ Medicolegal opioid questions } \\
\hline $\begin{array}{l}\text { Prescribing investigated, I am confident } \\
\text { I would pass }\end{array}$ & $46(37 \%)^{*}$ & $43(34 \%)^{*}$ & $28(22 \%)^{*}$ & $6(5 \%)$ & $3(2 \%)$ & $0(0 \%)$ & $93 \%$ \\
\hline $\begin{array}{l}\text { Unlawful to prescribe to a patient with } \\
\text { known substance abuse }\end{array}$ & $3(2)$ & $8(6)$ & $7(5)$ & $14(\mathrm{II})^{*}$ & $66(52)^{*}$ & $30(23)^{*}$ & 86 \\
\hline $\begin{array}{l}\text { Federal law permits post-dated } \\
\text { prescriptions }\end{array}$ & $5(4)$ & $21(16)$ & $4(3)$ & $14(\mathrm{II})^{*}$ & $42(33)^{*}$ & $42(34)^{*}$ & 78 \\
\hline $\begin{array}{l}\text { I know how to find state, federal } \\
\text { requirements }\end{array}$ & $18(14)^{*}$ & $45(35)^{*}$ & $22(17)^{*}$ & $23(18)$ & $17(13)$ & $2(2)$ & 67 \\
\hline $\begin{array}{l}\text { Illegal to prescribe methadone unless } \\
\text { addiction certified }\end{array}$ & $19(15)$ & $19(15)$ & $7(6)$ & $8(6)^{*}$ & $42(33)^{*}$ & $32(25)^{*}$ & 65 \\
\hline I understand state, federal requirements & $14(\mathrm{II})^{*}$ & $33(26)^{*}$ & $32(25)^{*}$ & $31(24)$ & $15(12)$ & $2(2)$ & 62 \\
\hline $\begin{array}{l}\text { Federal regulations limit the number } \\
\text { of prescribed dosages }\end{array}$ & $8(6)$ & $29(23)$ & $14(\mathrm{II})$ & $19(15)^{*}$ & $46(36)^{*}$ & II (9)* & 60 \\
\hline \multicolumn{8}{|l|}{ Clinical opioid questions } \\
\hline The elderly cannot tolerate opioids & $2(2)$ & $5(4)$ & $8(6)$ & $18(14)^{*}$ & $71(55)^{*}$ & $24(19)^{*}$ & 88 \\
\hline $\begin{array}{l}\text { Most common opioid adverse effect. } \\
\text { Answer: constipation }\end{array}$ & $110(86)^{* *}$ & - & - & - & - & $18(14)$ & 86 \\
\hline $\begin{array}{l}\text { Long-term NSAIDs have higher risks } \\
\text { than opioids }\end{array}$ & $7(5)^{*}$ & $4 \mathrm{I}(32)^{*}$ & $47(37)^{*}$ & $16(13)$ & $12(9)$ & $5(4)$ & 74 \\
\hline $\begin{array}{l}\text { No opioids for patients with a likely } \\
\text { drug abuser profile }\end{array}$ & $5(4)$ & $7(5)$ & $23(18)$ & $47(37)^{*}$ & $38(30)^{*}$ & $8(6)^{*}$ & 73 \\
\hline $\begin{array}{l}\text { No opioids for chronic pain of } \\
\text { unknown cause }\end{array}$ & $4(3)$ & $9(7)$ & $22(17)$ & $36(28)^{*}$ & $49(39)^{*}$ & $7(6)^{*}$ & 72 \\
\hline $\begin{array}{l}\text { Chronic opioid therapy has high risk } \\
\text { of addiction in adults }>40 \text { years of } \\
\text { age without history of } \\
\text { substance abuse }\end{array}$ & $I(I)$ & $22(17)$ & $24(19)$ & $27(2 I)$ & $40(3 I)$ & $14(11)$ & 63 \\
\hline $\begin{array}{l}\text { Morphine-induced sedation usually } \\
\text { clears with long-term use }\end{array}$ & $6(5)^{*}$ & $25(20)^{*}$ & $39(30)^{*}$ & $27(2 I)$ & $26(20)$ & $5(4)$ & 55 \\
\hline $\begin{array}{l}\text { Physiologic basis for pain should be } \\
\text { primary factor for opioids }\end{array}$ & $2(2)$ & $23(18)$ & $33(26)$ & $40(3 \mathrm{I})^{*}$ & $26(20)^{*}$ & $3(2)^{*}$ & 54 \\
\hline There is a ceiling dose for opioids & $8(6)$ & $26(20)$ & $25(20)$ & $20(16)^{*}$ & $36(28)^{*}$ & $13(10)^{*}$ & 54 \\
\hline $\begin{array}{l}\text { I am comfortable calculating } \\
\text { conversion doses of opioids }\end{array}$ & $12(9)^{*}$ & $21(16)^{*}$ & $35(27)^{*}$ & $29(23)$ & $22(17)$ & $9(7)$ & 53 \\
\hline $\begin{array}{l}\text { Analgesic tolerance limits long-term } \\
\text { opioid use }\end{array}$ & $4(3)$ & $30(23)$ & $35(27)$ & $25(20)^{*}$ & $32(25)^{*}$ & $2(2)^{*}$ & 46 \\
\hline
\end{tabular}

Notes: *Correct answer. **Multiple-choice single answer question where data for the correct answer given is shown in the "Strongly agree" column, and the data for the incorrect answer given is shown in the "Strongly disagree" column.

Abbreviation: NSAIDs, nonsteroidal anti-inflammatory drugs.

"Morphine-induced sedation is only a transient problem and will usually clear with continued use", "The presence of a physiologic basis for pain should be the primary factor when deciding to prescribe opiates", "I feel comfortable calculating conversion doses of commonly used opioids", "There is a limit or 'ceiling' to the dosage of pure agonist opioids [...] that can be used to control a patient's pain", and "I believe that analgesic tolerance to opioids usually limits long-term use". In a study by Lin et al, ${ }^{21} 27 \%$ of geriatric and internal medicine physicians reported, "I do not know how to prescribe the correct dose" as a reason they hesitated to prescribe opioids. A similar study of Canadian family medicine physicians found that respondents scored higher than $40 \%$ on only two of nine knowledge-based questions about the use of prescription opioids. ${ }^{13}$ A 2005 study of West Virginia family medicine physicians showed similar results in that respondents scored higher than $60 \%$ on only six of ten questions. ${ }^{10}$ Likewise, a small study of primary care providers showed gaps in knowledge related to opioid prescribing where only $69 \%$ of questions were correctly answered. ${ }^{12}$ These research findings are consistent with our current findings and support our previous observations ${ }^{15}$ that knowledge about chronic pain has not been consistently associated with knowledge about the use of prescription opioids. $5,7,8$ 
While there have been few studies using objective tools to evaluate providers' knowledge before and after an educational intervention, recognized knowledge gaps ${ }^{6,10,12,13,16,17,21}$ could be amenable to provider education. The observations from our survey study suggest that the educational interventions should be aimed toward enhancing knowledge about the clinical use of opioids compared with the medicolegal aspects of this form of pain therapy. This is particularly important as primary care providers consistently report low satisfaction with their formal training related to opioid management, ${ }^{5,10-12}$ and rate their clinical knowledge in this area as low. ${ }^{6}$ A 2007 study of primary care providers by $\mathrm{O}^{\prime}$ Rorke et $\mathrm{al}^{18}$ found that physicians who were most comfortable managing chronic pain had received training after residency. This was recently confirmed by Lalonde et $\mathrm{al}^{22}$ who reported that hours of CME focused on chronic pain were associated with higher scores on the KnowPain-50. These studies suggest that the postgraduate educational interventions may prove particularly effective for primary care providers who manage chronic pain. This supposition is supported by the findings of a recent prospective longitudinal study where primary care practitioners received education about the clinical management of chronic pain including management of patients receiving long-term opioid therapy. ${ }^{23}$ Compared with baseline, practitioners at 1-year follow-up reported improvements in feeling sufficiently trained to manage patients receiving long-term opioid therapy, improved perceived confidence in prescribing opioids, and improvements in identifying patients at risk for opioid misuse. ${ }^{23}$

\section{Limitations}

This study has limitations. Study participants were seeking CME regarding the management of chronic pain, and were potentially highly motivated to improve their knowledge about the management of chronic pain. Thus, selection bias could influence the generalization of the study observations to other populations of nonpain specialty providers. We did not differentiate by professional degree; thus, differences in professional training could have influenced the study findings. Recent advances in knowledge since publication of the KnowPain-50 suggests that the designated correct response to the question "Chronic opioid therapy has high risk of addiction in adults older than 40 years of age without history of substance abuse" may not be entirely accurate. ${ }^{24-26}$

\section{Conclusion}

In summary, nonpain specialty providers demonstrated gaps in knowledge about opioid prescribing. Lower scores on clinically based questions may indicate an opportunity to provide focused educational content about this important area of clinical practice. The key observations from this study could be useful in designing future educational modules for nonpain specialty providers.

\section{Disclosure}

The authors report no conflicts of interest in this work.

\section{References}

1. Manchikanti L, Helm S, 2nd, Fellows B, et al. Opioid epidemic in the United States. Pain Physician. 2012;15(3 Suppl):ES9-38.

2. Dowell D, Kunins HV, Farley TA. Opioid analgesics - risky drugs, not risky patients. JAMA. 2013;309(21):2219-2220.

3. Ballantyne JC, LaForge KS. Opioid dependence and addiction during opioid treatment of chronic pain. Pain. 2007;129(3):235-255.

4. Okie S. A flood of opioids, a rising tide of deaths. $N$ Engl J Med. 2010;363(21):1981-1985.

5. Hutchinson K, Moreland AM, de CWAC, Weinman J, Horne R. Exploring beliefs and practice of opioid prescribing for persistent non-cancer pain by general practitioners. Eur J Pain. 2007;11(1):93-98.

6. Keller CE, Ashrafioun L, Neumann AM, Van Klein J, Fox CH, Blondell RD. Practices, perceptions, and concerns of primary care physicians about opioid dependence associated with the treatment of chronic pain. Subst Abus. 2012;33(2):103-113.

7. Nwokeji ED, Rascati KL, Brown CM, Eisenberg A. Influences of attitudes on family physicians' willingness to prescribe long-acting opioid analgesics for patients with chronic nonmalignant pain. Clin Ther. 2007;29(Suppl):2589-2602.

8. Potter M, Schafer S, Gonzalez-Mendez E, et al. Opioids for chronic nonmalignant pain. Attitudes and practices of primary care physicians in the UCSF/Stanford Collaborative Research Network. University of California, San Francisco. J Fam Pract. 2001;50(2):145-151.

9. Vijayaraghavan M, Penko J, Guzman D, Miaskowski C, Kushel MB. Primary care providers' views on chronic pain management among highrisk patients in safety net settings. Pain Med. 2012;13(9):1141-1148.

10. Ponte CD, Johnson-Tribino J. Attitudes and knowledge about pain: an assessment of West Virginia family physicians. Fam Med. 2005; 37(7):477-480.

11. Upshur CC, Luckmann RS, Savageau JA. Primary care provider concerns about management of chronic pain in community clinic populations. J Gen Intern Med. 2006;21(6):652-655.

12. Jamison RN, Sheehan KA, Scanlan E, Matthews M, Ross EL. Beliefs and attitudes about opioid prescribing and chronic pain management: survey of primary care providers. J Opioid Manag. 2014;10(6): 375-382.

13. Allen MJ, Asbridge MM, Macdougall PC, Furlan AD, Tugalev O. Self-reported practices in opioid management of chronic noncancer pain: a survey of Canadian family physicians. Pain Res Manag. 2013;18(4):177-184.

14. Bhamb B, Brown D, Hariharan J, Anderson J, Balousek S, Fleming MF. Survey of select practice behaviors by primary care physicians on the use of opioids for chronic pain. Curr Med Res Opin. 2006; 22(9):1859-1865.

15. Hooten WM, Bruce BK. Beliefs and attitudes about prescribing opioids among healthcare providers seeking continuing medical education. J Opioid Manag. 2011;7(6):417-424.

16. Wolfert MZ, Gilson AM, Dahl JL, Cleary JF. Opioid analgesics for pain control: Wisconsin physicians' knowledge, beliefs, attitudes, and prescribing practices. Pain Med. 2010;11(3):425-434.

17. Tournebize J, Gibaja V, Muszczak A, Kahn JP. Are physicians safely prescribing opioids for chronic noncancer pain? A systematic review of current evidence. Pain Pract. Epub 2015 Apr 10. 
18. O'Rorke JE, Chen I, Genao I, Panda M, Cykert S. Physicians' comfort in caring for patients with chronic nonmalignant pain. Am J Med Sci. 2007;333(2):93-100.

19. Harris JM, Jr., Fulginiti JV, Gordon PR, et al. KnowPain-50: a tool for assessing physician pain management education. Pain Med. 2008;9(5):542-554.

20. US Department of Health and Human Services. Code of Federal Regulations. Available from: http://www.hhs.gov/ohrp/humansubjects/ guidance/45cfr46.html. Accessed December 7, 2015.

21. Lin JJ, Alfandre D, Moore C. Physician attitudes toward opioid prescribing for patients with persistent noncancer pain. Clin J Pain. 2007;23(9):799-803.

22. Lalonde L, Leroux-Lapointe V, Choiniere M, et al. Knowledge, attitudes and beliefs about chronic noncancer pain in primary care: a Canadian survey of physicians and pharmacists. Pain Res Manag. 2014;19(5):241-250.

23. Jamison RN, Scanlan E, Matthews ML, Jurcik DC, Ross EL. Attitudes of primary care practitioners in managing chronic pain patients prescribed opioids for pain: a prospective longitudinal controlled trial. Pain Med. Epub 2015 Aug 25.
24. Chou R, Fanciullo GJ, Fine PG, et al. Clinical guidelines for the use of chronic opioid therapy in chronic noncancer pain. J Pain. 2009;10(2):113-130.

25. Deb I, Chakraborty J, Gangopadhyay PK, Choudhury SR, Das S. Single-nucleotide polymorphism (A118G) in exon 1 of OPRM1 gene causes alteration in downstream signaling by mu-opioid receptor and may contribute to the genetic risk for addiction. $J$ Neurochem. 2010;112(2):486-496.

26. Doehring A, Hentig N, Graff J, et al. Genetic variants altering dopamine D2 receptor expression or function modulate the risk of opiate addiction and the dosage requirements of methadone substitution. Pharmacogenet Genomics. 2009;19(6):407-414.
Journal of Pain Research

\section{Publish your work in this journal}

The Journal of Pain Research is an international, peer-reviewed, open access, online journal that welcomes laboratory and clinical findings in the fields of pain research and the prevention and managemen of pain. Original research, reviews, symposium reports, hypothesis formation and commentaries are all considered for publication.

\section{Dovepress}

The manuscript management system is completely online and includes a very quick and fair peer-review system, which is all easy to use. Visit http://www.dovepress.com/testimonials.php to read real quotes from published authors.

\footnotetext{
Submit your manuscript here: http://www.dovepress.com/journal-of-pain-research-journal
} 